\title{
APPLICATION OF ADDITIVELY MANUFACTURED POLYMER COMPOSITE PROTOTYPES IN FOUNDRY
}

\author{
Wiesław Kuczko', Radosław Wichniarek' ${ }^{1}$, Filip Górski' ${ }^{1}$ Paweł Buń1, Przemysław Zawadzki ${ }^{1}$
}

1 Chair of Management and Production Engineering, Poznań University of Technology, Piotrowo 3, 60-965 Poznań, Poland, e-mail: wieslaw.kuczko@put.poznan.pl; radoslaw.wichniarek@put.poznan.pl; filip.gorski@ put.poznan.pl; pawel.k.bun@doctorate.put.poznan.pl; przemyslaw.zawadzki@put.poznan.pl

Received: 2015.04.10 Accepted: 2015.05 .08 Published: 2015.06.01

\begin{abstract}
The paper presents a method, developed by the authors, for manufacturing polymer composites with the matrix manufactured in a layered manner (via 3D printing Fused Deposition Modeling) out of a thermoplastic material. As an example of practical application of this method, functional prototypes are presented, which were used as elements of foundry tooling - patterns for sand molding. In case of manufacturing prototype castings or short series of products, foundries usually cooperate with modeling studios, which produce patterns by conventional, subtractive manufacturing technologies. If patterns have complex shapes, this results in high manufacturing costs and significantly longer time of tooling preparation. The method proposed by the authors allows manufacturing functional prototypes in a short time thanks to utilizing capabilities of additive manufacturing (3D printing) technology. Thanks to using two types of materials simultaneously (ABS combined with chemically hardened resins), the produced prototypes are capable of carrying increased loads. Moreover, the method developed by the authors is characterized by manufacturing costs lower than in the basic technology of Fused Deposition Modeling. During the presented studies, the pattern was produced as a polymer composite and it was used to prepare a mold and a set of metal castings.
\end{abstract}

Keywords: additive manufacturing, Fused Deposition Modelling, foundry tooling.

\section{INTRODUCTION}

The Additive Manufacturing Technologies (AMTs), widely known under the name of "3D printing" are more and more widespread in various branches of industry. They become a crucial tool, allowing the companies to significantly reduce time of preparation of a product for manufacturing, which results in a significant reduction of costs of implementing a new product into market. Among many advantages of the AMTs, the most important are: lack of need for manufacturing of special tooling, manufacturing directly from the digital CAD model, wide range of available devices and applied materials (ceramics, plastics, waxes, metals). Thanks to building a product layer by layer, it is possible to drop prac- tically all the manufacturing limitations regarding shape complexity of a product, which are present in conventional manufacturing technologies (machining, foundry, plastic forming).

Among many AMT methods, the Fused Deposition Modeling is one of the most widespread and globally available technologies. The reason for this is a relatively low cost of buying and using a machine for production and non-complex and eco-friendly process (odorless and non-toxic material, minimal waste volume, low energy consumption). The mechanical properties of the FDM products are good enough to use them as visual or concept prototypes, mock-ups or design aids. In case of a production of short series of products or functional prototypes, the strength of the FDMmade products is often not satisfying [1]. 
Foundries are production plants which have one of the largest necessities for functional prototypes, especially if it comes to specialization in short series of individualized castings. Manufacturing of the special tooling (e.g. models for sand molds) through conventional machining is very costly and in many cases economically ineffective. An alternative is manual prototype production by experienced model-makers. Disadvantage of this method is an insufficient accuracy of the obtained models and time consumption, that is why foundries are constantly looking for new solutions. The research work focused on possibility of application of Rapid Prototyping or Rapid Tooling techniques (utilizing the AMTs) in foundry are conducted widely in the world $[2,3$, 4]. However, applications of prototypes made by FDM technology are usually limited to serving as a pattern for making silicone molds, which are further used to cast wax models for investment casting $[5,6]$.

Requirements regarding prototypes formulated by the companies which use the sand mold casting are usually as following:

- appropriate mechanical properties allowing to use the prototype for making many molds,

- high dimensional accuracy,

- rapid time of manufacturing,

- possibly low cost of making the prototype.

The Fused Deposition Modeling technology allows making prototypes with sufficient accuracy. However, in order to ensure a proper strength, the prototype must be built with a solid, monolithic internal filling (deposing material inside the part in a form of strictly adhering paths). It is directly transferred to the amount of material used in the manufacturing process and time of the process, which significantly affects the final price of the prototype. On the basis of many years of experience, the authors can state that almost $80 \%$ of enquired, needed prototypes are not produced because the price is too high. The method proposed by the authors - described on the example of a certain case study in this paper - allows reduction of these costs by limiting the use of material and shortening the manufacturing time in the Fused Deposition Modeling technology. Thanks to possibility of controlling the parameter of internal filling degree, the volume of material used for its manufacturing can be reduced, depending on the model size and shape, from several up to several dozen percent. It is directly transferred to reduc- tion of the manufacturing time. Such a prototype can be, however, used only as a visual model due to its low strength [7]. A solution for making partially filled, usable and strong models is the authors' patented technology of filling inside of a model with a liquid, chemically hardened resin. It allows using such models as elements of foundry tooling because they become strong, but the filling does not significantly increase their costs and allows keeping the manufacturing time acceptable.

\section{THEORETICAL INFORMATION}

The FDM method consists in linear deposition of plasticized thermoplastic material, extruded by a nozzle of a small diameter (for the BST 1200 device used in the studies described in this paper, the nozzle diameter is $0.4 \mathrm{~mm}$ ) by a special head, which can move in two axes ( $\mathrm{X}$ and $\mathrm{Y}$ ), in parallel to the modeling table. After building a geometry inside a given layer, the table changes its position regarding the head ( $\mathrm{Z}$ axis of the machine) by a defined value of the layer thickness (for the used BST 1200 device, $0.25 \mathrm{~mm}$ and $0.33 \mathrm{~mm}$ layer thicknesses are available). The extruded material solidifies in contact with the previously deposed layer, creating a stable connection. To ensure the support for geometries which protrude out of the contour of a previous layer significantly, it is necessary to build special support structures. They are also made out of thermoplastic material, but this material has different properties (namely, lower adhesion) - it is possible to mechanically separate them from the main part after the manufacturing process is finished [8].

The most frequently used FDM material is the acrylonitrile - butadiene - styrene (ABS), which ensures a relatively good strength and allows further processing of the manufactured objects (grinding, painting, gluing etc.) [9]. In the FDM method, it is possible to manufacture elements with the solid or sparse internal filling (Fig. 1a and 1b).

In the practical industrial applications, very often the elements manufactured additively are subjected to complex loads. An example of such loading is manufacturing of molds for casting in the mold sands. During the mechanical consolidation of the mold sand, the prototype (used as a pattern) is loaded by multiple forces, which leads to a complex stress state inside the part. The forces act in a dynamic way, which usually leads to failure of prototypes with the partial (sparse) 


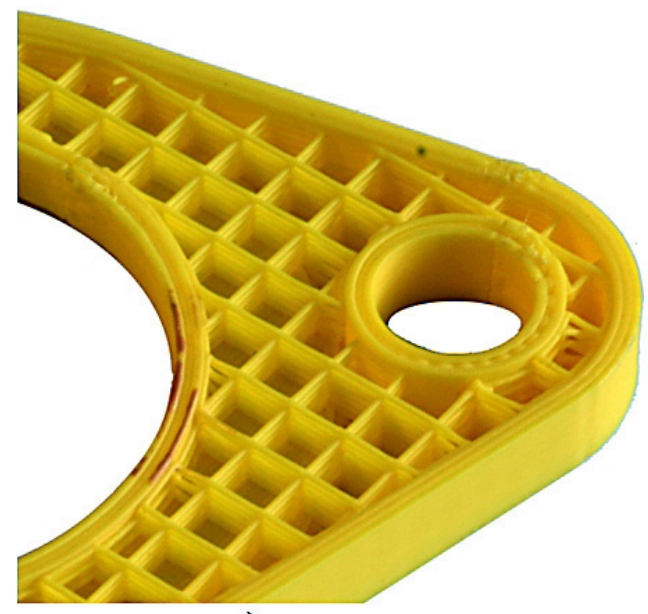

a)

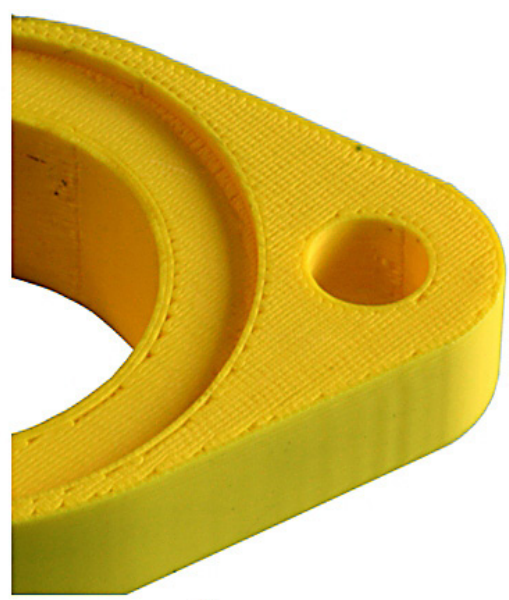

b)

Fig. 1. Prototypes made using the FDM method with filling: a) sparse (partial), b) solid (full)

filling. That is why the authors have proposed an alternative method of manufacturing of the sparse prototypes, in which the empty spaces are filled with a liquid resin, forming a fibrous composite. Two phases can be distinguished in such a composite: the matrix, made out of the ABS material using the FDM process and the reinforcement in a form of resin (Fig. 2).

Usually, in case of traditional composites, the internal fibers are a reinforcement, while the matrix holds the shape of the object and fixes the composite together. In case of a composite proposed by the authors, the contour produced using the FDM technology is the final product shape, while the resin ensures better mechanical properties [10].

Method of manufacturing the composite prototypes of matrix according to the FDM process and filled with a resin was patented by the authors in the Patent Office of Republic of Poland [11].
The developed method allows, depending on the used resin and the level of complexity of the matrix geometry, to conduct the filling process while the FDM process is still running or then it is finished and the support structures are removed.

\section{STUDY DESCRIPTION}

The model described in this paper is a casting of a faucet for spring for water tapping. Because of a characteristic shape of the faucet model, which was inspired by a shell, it was not possible to use a solution in a form of a ready product available in catalogues of the fittings producers. The model of the faucet was designed as stylistically coherent with the whole spring tap concept, so the prototype of a functional casting needed to be produced, for a fair event presentation. Figure 3 presents a final

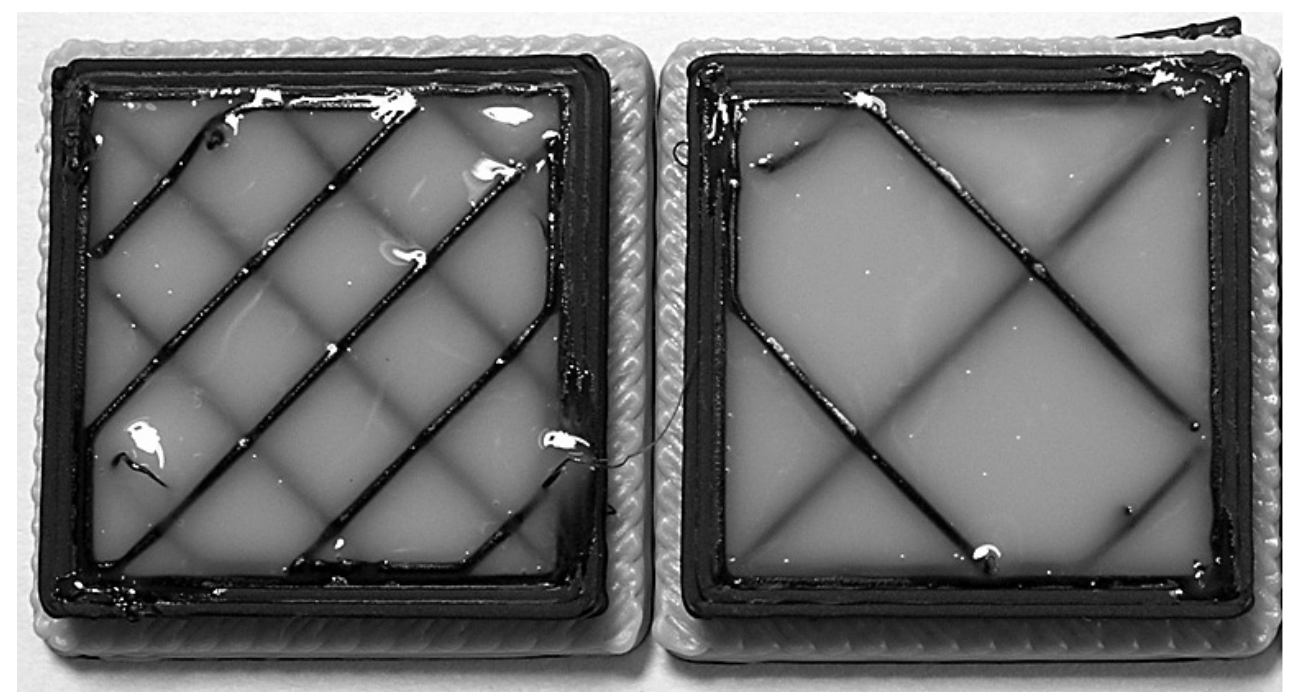

Fig. 2. Fibrous composite with the FDM-made matrix, filled with resin 


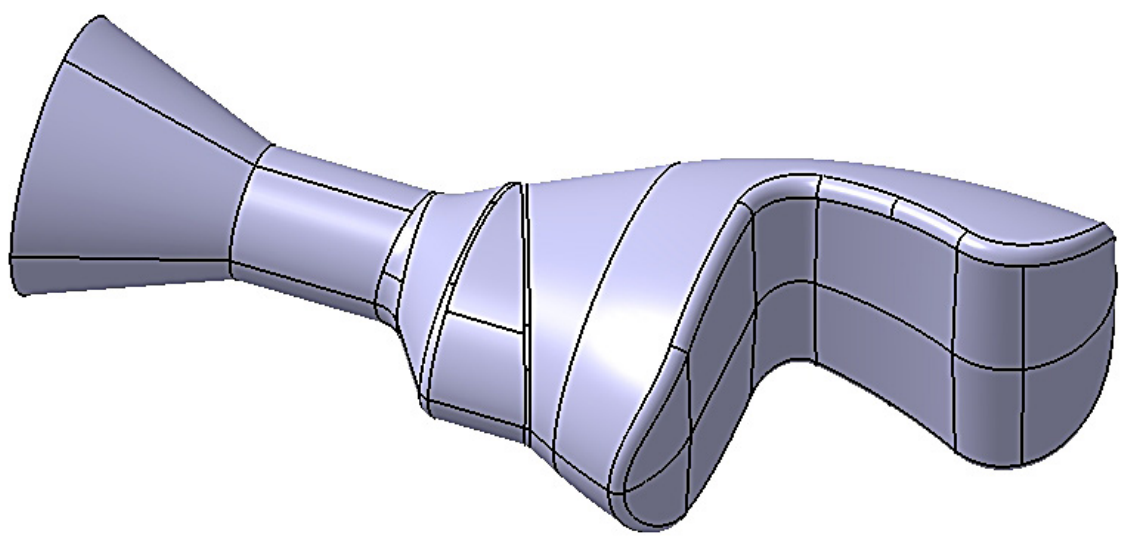

Fig. 3. Model of the faucet with the gating system

3D model of the faucet with the designed gating system, shaft element later used as a fixture, introduced drafts and allowances for shrinkage of brass, out of which the element was planned to be casted.

The model was divided into two halves. Each half was converted into a triangular mesh and saved to the STL format. After importing the model to the system controlling the FDM machine, it was sliced into layers of $0.254 \mathrm{~mm}$ thickness (103 layers total) and paths for the machine head deposing the model material were generated. For making the matrix of the ABS-resin composite, the Dimension BST 1200 machine from the Stratasys company was used. The material of the matrix was the ABS material of P400 type, colored in black. To shorten time of manufacturing the matrix, the partial internal filling was introduced with the maximum possible thread separation distance, equal to $12.7 \mathrm{~mm}$. Because of the complex shape of the prototype, filling the matrix was realized gradually, during the FDM manufacturing process. To fill the whole matrix correctly, the first filling was performed after the layer no. 43 was deposed (Fig. 4a), while the second one after the layer no. 90 was deposed (Fig. 4b).

To fill the matrix, polyurethane, chemically hardened resin Axson F19 was used. The filling was conducted gravitationally. The polyurethane resin was decided to be used as a reinforcement of the composite, because it makes good adhesive connection with the ABS material and has generally good mechanical properties [12]. The polyurethane resins also have good castability, which makes filling of the matrix internal space easier. Their lifetime is long enough to perform the whole process without perturbations. Other advantages of the polyurethane resins include low shrinkage during hardening and low chemical aggressiveness. After hardening process is

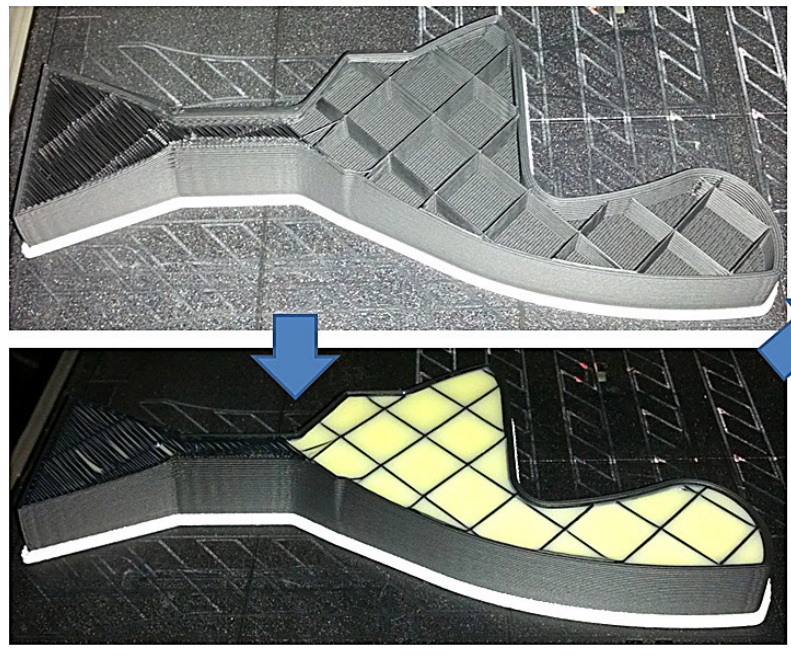

a)

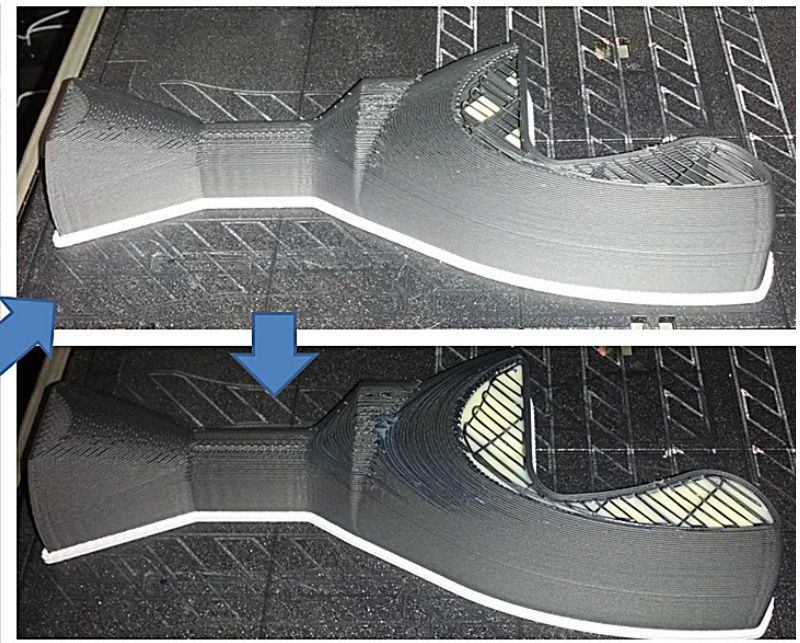

b)

Fig. 4. Stages of filling the matrix with the resin: a) filling after layer 40, b) filling after layer 90 
finished, the resin is not a toxic waste and there is no problem with its utilization. Its relatively low price is also an important factor - it is less costly than the ABS material (used in commercial FDM systems), which allows to make the functional monolithic prototypes in a less expensive way.

After the FDM process was finished, the prototype was left until the resin was totally hardened, then the support material was removed (gray material visible in the Figure 4). The products manufactured additively are characterized with the staircase effect on their surface. It is related to characteristics of the FDM process itself - deposing the ABS material threads layer by layer. The layer thickness has direct influence on the size of the staircase effect. In the described case, the applied layer thickness was equal to $0.254 \mathrm{~mm}$ (the lowest possible value for the used BST 1200 machine) what was not sufficient to obtain a proper surface quality The prototype was subjected to the post-processing in form of grinding. In Figure 5, the prototype after removal of the support material is shown (staircase effect visible).
Despite low shrinkage of the F19 resin (not exceeding 1\%), its influence on dimensional and shape accuracy of the obtained composite was also studied. The finished prototype and the matrix itself have been measured using a 3D scanner Atos Compact Scan 5M and then compared with each other, the results were presented in a form of a colored deviation map. The next stage was preparation of a pattern plate and a molding box. Both halves of the faucet were based to each other using fixing pins and assembled mechanically to the pattern plate made out of plywood of $10 \mathrm{~mm}$ thickness (Fig. 6a). Other elements of the molding box were also manufactured out of plywood. The assembled box is presented in Figure 6b. To make the mold, molding sand composed from quartz sand mixed with liquid sodium glass. After the box was filled, the sand was consolidated mechanically and hardened by blowing carbon dioxide through it. One half of the ready mold is presented in Figure 6c.

The prepared mold was filled with a liquid brass, then it was opened and the casting was cleaned. The Figure 7 presents the obtained raw
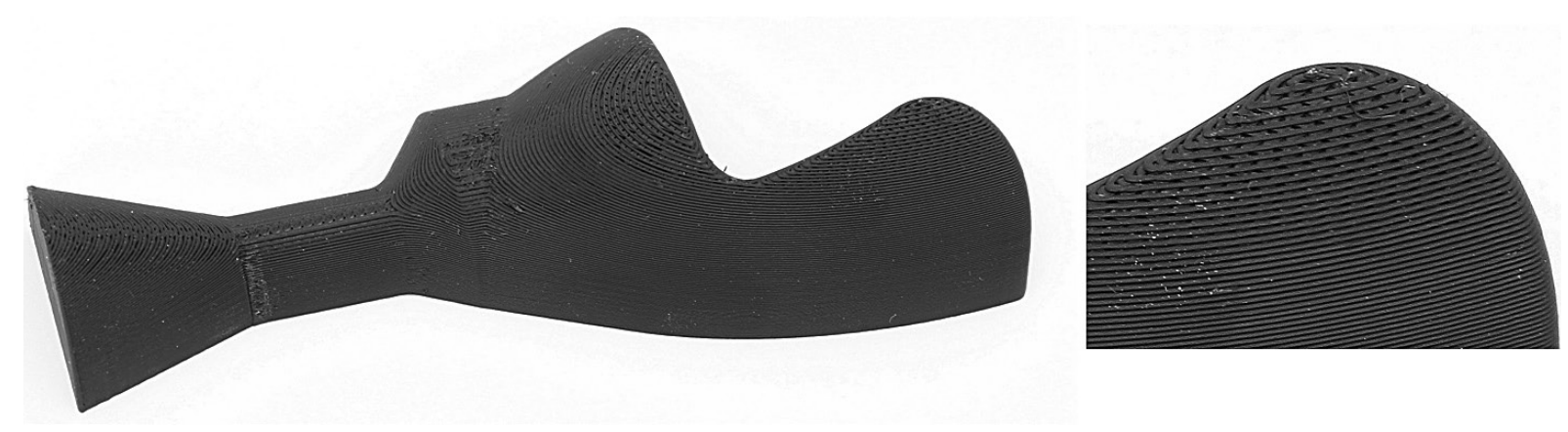

Fig. 5. The prototype after removal of the support material (staircase effect visible)

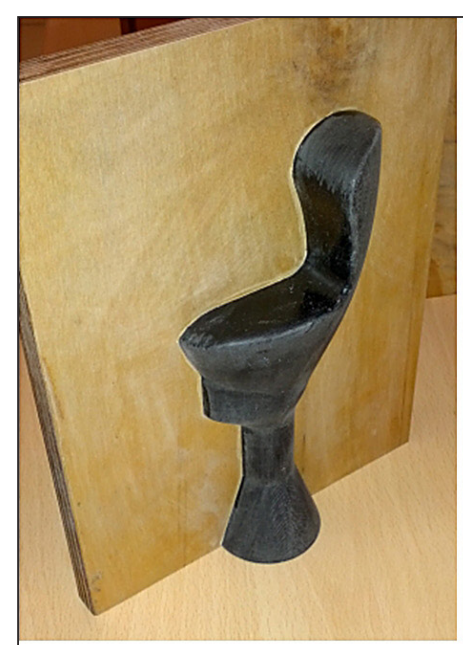

a)

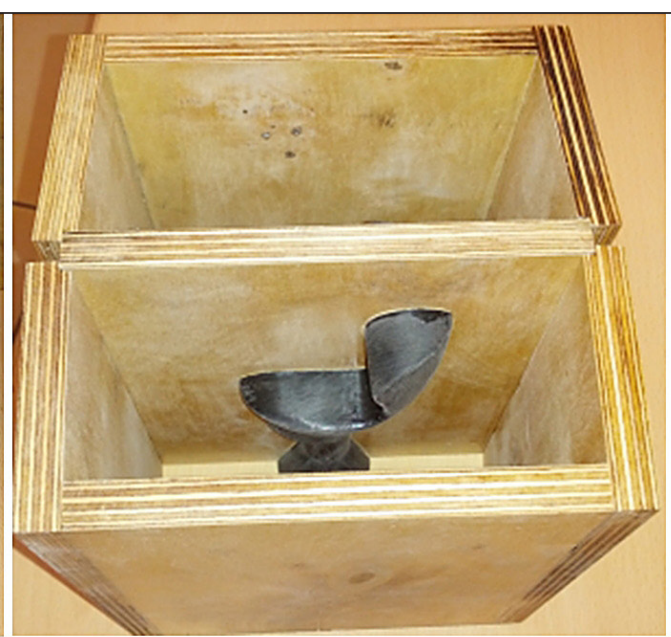

b)

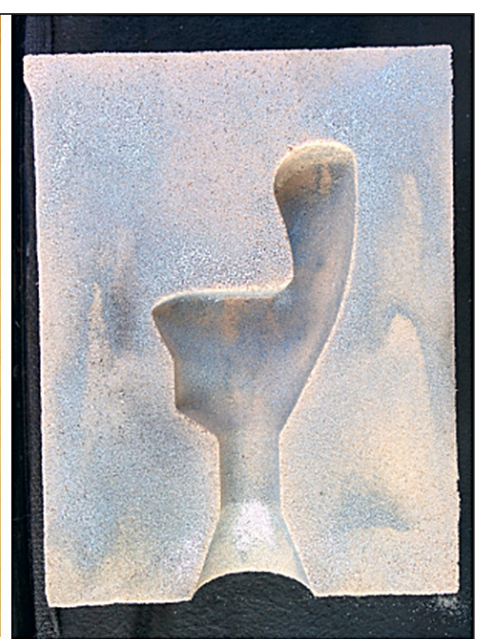

c)

Fig. 6. a) pattern plate with the composite prototype, b) ready molding box, c) the mold 
casting. The casting was subjected to machining (milling of allowances, drilling holes, threading) and then galvanized, to put a chrome coating on its surface. A final product - the faucet - is presented in the Figure 8.

To study the economical aspect of the production of composite prototypes in relation to the production of prototypes with solid internal filling with the FDM method, the setup times were measured, as well as times of manufacturing prototypes of the same geometry with both methods. The costs of used materials were also taken into account.

\section{RESULTS DISCUSSION}

Use of composite products with matrix manufactured using the FDM method and filled with a polyurethane resin as a foundry tooling (a pattern) have proven an efficiency of the proposed methodology. As opposed to prototypes with the sparse internal filling, the produced composite prototypes were characterized with an appropriate strength and ability to carry loads related to the process of consolidation of the applied molding sand. The authors have also prepared a pattern plate with a prototype made solely out of ABS material with the sparse filling. During the process of mechanical consolidation of the molding sand, the prototype was destroyed - disjoint of threads of the ABS plastic occurred in the area where the staircase effect was most apparent (Fig. 5). Under pressure of the molding sand, the outer layer of the material collapsed to the inside, destroying the internal framework of the partial internal filling. It was therefore proven that the FDM process with the partial filling is not a viable option to prepare patterns for castings from the sand molds.

Total time of manufacturing of both halves of the prototype with the monolithic (solid) internal filling was 280 minutes, while the time of manufacturing the matrix itself with the internal thread distance equal to $12.7 \mathrm{~mm}$ was 133 minutes. The

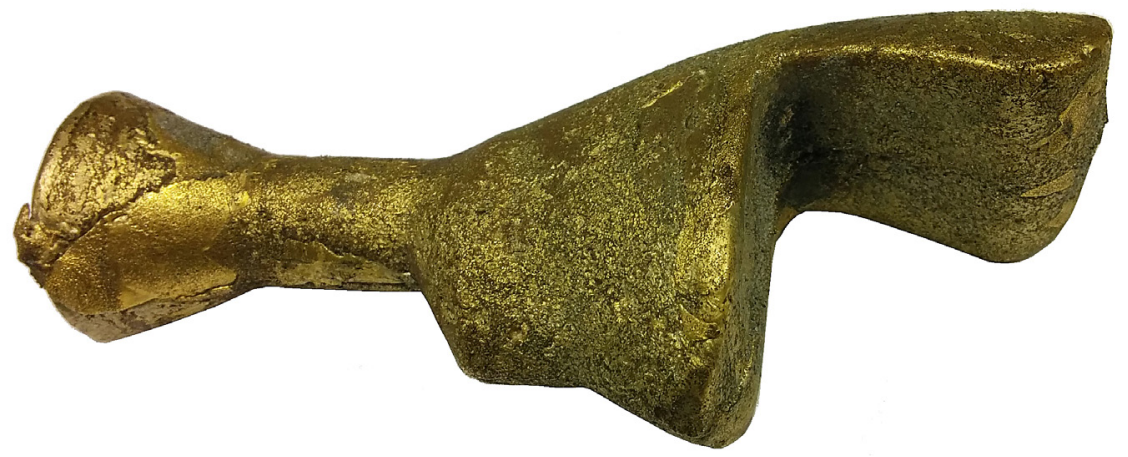

Fig. 7. The raw casting

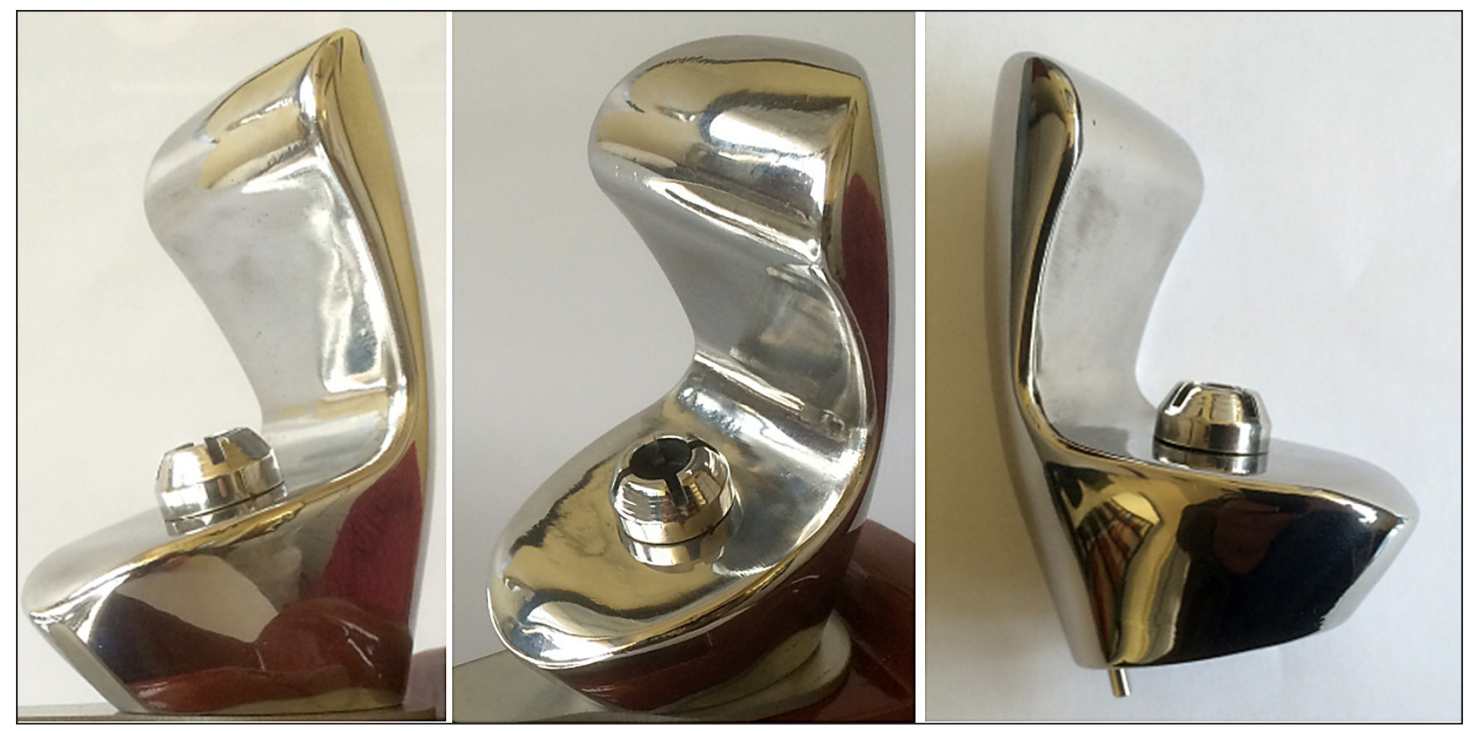

Fig. 8. Final product - the faucet of a spring for water tapping 
total time of manufacturing the composite prototypes, considering the matrix production time, time of filling it with the resin and time needed for resin hardening was 250 minutes. For the prototypes of solid internal filling, $273 \mathrm{~cm}^{3}$ of the P400 ABS material was used, while the composite prototypes required $51 \mathrm{~cm}^{3}$ of the same ABS material and $260 \mathrm{~cm}^{3}$ of the Axson F19 resin.

Table 1 presents a juxtaposition of costs and time of manufacturing of the prototype of the faucet pattern using both approaches (standard and proposed by the authors).

The Figure 9 presents results of comparison of the matrix manufactured using the FDM method with the partial filling and the composite prototype (the same matrix after filling it with the resin).

An average error of fitting both models was $0.06 \mathrm{~mm}$. The greatest deviation is present in the end part of the faucet (red and navy blue color). The deviation in these areas is equal to $0.26 \mathrm{~mm}$ in the bottom part and $-0.24 \mathrm{~mm}$ in the upper part, which indicates that a local deformation is present (buckling directed to the bottom part). In case of $85 \%$ of the other points, the deviations are inside accuracy and repeatability of the BST1200 machine, which is $\pm 0.2 \mathrm{~mm}$.

\section{CONCLUSIONS}

The studies conducted by the authors have proven, that the developed method of manufacturing the composite prototypes can be used for production of patterns for foundry. Thanks to the use of the FDM process to build the composite matrix (which is an external shell of the composite), it is possible to obtain an accurate representation of the desired shape, while the application of a polyurethane resin for filling the inside of the matrix makes it possible to increase the total strength of the product. Moreover, selection of resins of appropriate properties is possible (such as increased hardness, abrasion resistance or other properties), which will affect the final properties of the composite. The applied Axson F19 resin is much cheaper than the ABS P400 material used in the BST1200 machine, which allowed reduction of the material costs to $59 \%$ in the described case. The total manufacturing time was also shortened by $24 \%$. It is noteworthy that the total composite manufacturing time presented in the paper includes also the time needed for solidification (hardening) of the resin (90 minutes for the described case). The hardening is realized outside the building chamber of the FDM machine, which is an additional advantage - time of operation of the device is only $50 \%$ of time needed for manufacturing a prototype of the same geometry, but with the solid internal filling. Still, the attention must be paid to the fact, that the presented times can be very different for different geometries.

The methodology of manufacturing composite prototypes developed and patented by the authors is currently used in the Laboratory of Rapid Manufacturing of Poznan University of Technology during cooperation with industrial companies for making functional prototypes. The authors are also continuing work aimed at determination of how the basic properties of the obtained composites change depending on the type of applied resin.

Table 1. Comparison of times and costs of materials for manufacturing of monolithic and composite prototypes

\begin{tabular}{|l|c|c|c|c|}
\hline \multirow{2}{*}{ Manufacturing of composite prototypes } & \multicolumn{2}{|c|}{ Total relative manufacturing time } & \multicolumn{2}{|c|}{ Relative cost of the used material } \\
\cline { 2 - 5 } & {$[\mathrm{min}]$} & {$[\%]$} & {$[\mathrm{PLN}]$} & {$[\%]$} \\
\hline FDM-made ABS prototype with solid filling & 280 & 100 & 456.00 & 100 \\
\hline ABS-resin composite prototype & 250 & 89.3 & 111.00 & 24.3 \\
\hline
\end{tabular}
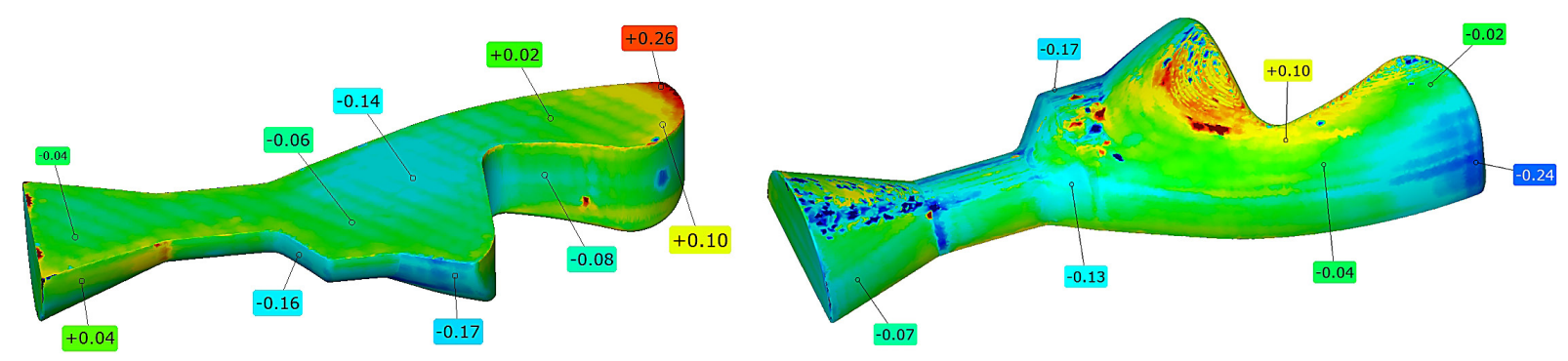

Fig. 9. Comparison of the matrix manufactured using the FDM method with the composite prototype (matrix filled with resin) 


\section{REFERENCES}

1. Kuczko W., Wichniarek R., Górski F.: Odtwarzanie zużytych lub zniszczonych elementów maszyn za pomocą inzynierii odwrotnej oraz technik szybkiego wytwarzania. Inżynieria Maszyn (Journal of Machine Engineering), 18(1), 2013, 3-7.

2. Rosochowski A., Matuszak A.: Rapid tooling: the state of the art. Journal of Materials Processing Technology, 106, 2000, 191-198.

3. Wang W., Conley J.G., Stoll H.W.: Rapid tooling for sand casting using laminated object manufacturing process. Rapid Prototyping Journal 5, 1999, 134-140.

4. Cheah C.M., Chua C.K., Lee C.W., Feng C., Totong K.: Rapid prototyping and tooling techniques: a review of applications for rapid investment casting. The International Journal of Advanced Manufacturing Technology 25, 2005, 308-320.

5. Lee C.W., Chua C.K., CheahC.M., Tan L.H., Feng C.: Rapid investment casting: direct and indirect approachesvia fused deposition modelling The International Journal of Advanced Manufacturing Technology 23, 2004, 93-101.

6. Raju B.S., Chandrashekar U., Drakshayani D.N., Chockalingam K.: Internet based e-manufacturing of prototypes for one-off intricate castings by using rapid prototyping technology. International Journal of Applied Engineering Research, 5(20), 2010, 3357-3365.

7. Sood A.K., Ohdar R.K., Mahapatra S.S.: Parametric appraisal of mechanical property of fused deposition modeling processed parts. Materials and Design, 31, 2010, 287-295.

8. Kuczko W., Wichniarek R., Górski F.: Influence of process parameters on dimensional accuracy of parts manufactured using Fused Deposition Modelling technology. Advances in Science and Technology Research Journal, 7(19), 2013, 27-35.

9. Kuczko W., Wichniarek R., Górski F.: Influence of filling type on strength of parts manufacured by Fused Deposition Modelling. Journal of Machine Engineering, 14(3), 2014, 113-125.

10. Oczoś K.: Kompozyty włókniste - właściwości, zastosowanie, obróbka ubytkowa. Mechanik 7, 2008, p. 579.

11. Kuczko W., Wichniarek R.: Sposób wytwarzania kompozytowych wyrobów o osnowie z tworzywa termoplastycznego (,Method of manufacturing of composite products with the matrix out of thermoplastic material"), patent no P.401988, date: 10.12.2012.

12. Arenas J., Alia C., Blaya F., Sanz A.: Multi-criteria selection of structural adhesives to bond ABS parts obtained by rapid prototyping. International Journal of Adhesion \& Adhesives 33, 2012, 67-74. 